\title{
İşsizlik Histerisinin Geçerliliğin Sınanması: E7 Ülkelerine İlişkin Ampirik Bir Çalışma
}

\author{
DOI: 10.26466/opus.730129
}

*

\section{Yusuf Bozgeyik *}

* Dr.Öğr. Üyesi, Gaziantep Üniversitesi, İïBF, Maliye Bölümü, Gaziantep/Türkiye

E-Posta: ybozgeyik@gantep.edu.tr

ORCID: $0000-0003-2613-2792$

\section{Öz}

Veri ücret düzeyinde çalı̧̧mak isteyip iş bulamayanlar olarak tanımlanan işsizlik, özellikle gelişmekte olan ülkelerin temel sorunlarından birisidir. Yüksek işsizlik Türkiye gibi gelişmekte olan ülkeler için uzun yıllar çözüm bekleyen temel ekonomik sorunlar arasındadır. Tam istihdam düzeyindeki işsizlik oran gösteren doğal işsizliğe ulaşmak, ekonomi yönetimlerinin istihdam politikalarındaki temel hedefi konumundadır. Isssizlik histerisinin varlı̆̆ı, gelişmiş ve gelişmekte olan ülkelerin ekonomi yönetimleri açısından önem arz etmektedir. İşsizlik oranlarının şoklardan sonra ortalamaya dönme eğiliminde olması durumunda ilgili politikalara aktif bir şekilde müdahale etmeleri gerekmektedir. Yapılan çalışmalarda işsizlik histerisinin geçerliliği hakkında bir görüş birliği olmadiğı görülmektedir. Bu çalışmada gelişmekte olan E7 ülkelerinde işsizlik histerisinin geçerliliği incelenecektir. Bu doğrultuda E7 ülkelerine ait 1991-2018 dönemi yıllık işsizlik oranları analize dahil edilmiştir. Öncelikle serilerin doğrusallı̆̆ incelenmiştir. Doğrusal özellikte olan işsizlik oranı serilerine yapısal kırılmalı birim kök testleri uygulanmıştır. Doğrusal olmayan serilere ise doğrusal olmayan birim kök testleri uygulanmıştır. Analiz sonucunda Çin dışında diğer ülkelerde işsizlik histerisinin geçerli olmadığı görülmektedir.

Anahtar Kelimeler: ̇ंşsizlik Histerisi, Gelişmekte Olan Ülkeler, Birim Kök Testleri. 


\title{
Examining Validation of Unemployment Hysteresis: An Empirical Study on E7 Countries
}

\begin{abstract}
Unemployment, which is defined as those who want to work at the data wage level but cannot find a job, is one of the main problems of developing countries. High unemployment solutions for many years for developing countries such as Turkey is among the outstanding basic economic problems. Achieving natural unemployment, which shows the unemployment rate at full employment level, is the main target of economic administrations in employment policies. The presence of unemployment hysteresis is important for the economic management of developed and developing countries. If unemployment rates tend to return to average after shocks, they need to actively intervene in related policies. In the studies conducted, it is seen that there is no consensus about the validity of the unemployment hysteresis. This study will examine the validity of the unemployment hysteresis in developing E7 countries. Accordingly, the annual unemployment rates of the E7 countries for the period 1991-2018 are included in the analysis. First of all, the linearity of the series was examined. Structural fracture unit root tests were applied to the unemployment rate series, which are linear. Nonlinear series were applied to non-linear unit root tests. As a result of the analysis, it is seen that unemployment hysteria is not valid in other countries except China.
\end{abstract}

Keywords: Unemployment Hysteresis, Developing Countries, Unit Root Tests 


\section{Giriş}

Veri ücret düzeyinde çalışmak isteyip iş bulamayanlar olarak tanımlanan işsizlik, özellikle gelişmekte olan ülkelerin temel sorunlarından birisidir. Enflasyon gibi başka ekonomik sorunlarla birlikte yaşandığında ise gelişmekte olan ekonomiler için daha köklü sorun haline gelmektedir. 1956 yılında Philips eğrisi ile açılanan enflasyon ile işsizlik arasındaki ilişki, 1970 petrol krizi ile birlikte sorgulanmaya başlanmış ve stagflasyon krizi ile birlikte farklı iktisat politikalarının ortaya çıkmasına neden olmuştur.

Yüksek işsizlik Türkiye gibi gelişmekte olan ülkeler için uzun yıllar çözüm bekleyen temel ekonomik sorunlar arasındadır. Tam istihdam düzeyindeki işsizlik oranı gösteren doğal işsizliğe ulaşmak, ekonomi yönetimlerinin istihdam politikalarındaki temel hedefi konumundadır. 1980-2000 yılları arasında tek haneli rakamlarda seyreden işsizlik oranı 2001 Şubat krizi ile birlikte çift haneli rakamlara ulaşmış ve günümüzde $\% 13$ dolayında seyretmektedir. ${ }^{1}$

Türkiye'de uzun dönem işsizlik rakamları incelendiğinde (bu durum genellikle doğal işsizlik oranı olarak kabul edilir), ekonomide işsizlik histerisinin olmadığı söylenebilir. İşsizlik rakamlarını yükselmesinin nedeni Türkiye gibi gelişmekte olan ülkelerde ekonomik krize dayalı olduğu söylenebilir.

Türkiye'ye benzer şekilde gelişmekte olan ülkelerde, yükselen ekonomileri gösteren E7 (Emerging Seven- Brezilya, Çin, Hindistan, Endonezya, Meksika, Rusya ve Türkiye) ülkelerinde de genellikle işsizlik histerisinin olmadığı ortaya konulmuştur. Bu ülkelerde işsizlik oranının yüksek seyretmesinin nedenini, histeri dışında işsizliği etkileyen diğer ekonomik faktörlerde aramak gereklidir. 2008 mortgage krizi sonrası AB ülkeleri gibi E7 ülkeleri de ekonomik krizden etkilenmiş ve işsizlik oranları bu durumdan olumsuz etkilenmiştir.

Tablo 1'de E7 ülkelerine ait işsizlik oranları gösterilmektedir. Tablo 1'e göre Türkiye' nin işsizlik oranında diğer gelişmekte olan ülkelere göre negatif ayrıştığ söylenebilir. Bu durum Türkiye'nin seçilen zaman periyodunda diğer ülkelere göre ekonomik sıkıntılar dışında siyasi sorunlar ve jeopolitik riskler yaşamasından da kaynaklanmaktadır.

\footnotetext{
${ }^{1}$ TÜiK Veritabanı- http://www.tuik.gov.tr/UstMenu.do?metod=temelist
} 
Tablo 1. E7 Ülkeleri İşsizlik Oranlan

\begin{tabular}{|c|c|c|c|c|c|c|c|}
\hline & Brezilya & Çin & Hindistan & Endonezya & Meksika & Rusya & Türkiye \\
\hline 1991 & 6.26 & 2.40 & 2.36 & 2.54 & 3.05 & 5.07 & 8.21 \\
\hline 1992 & 6.42 & 2.40 & 2.41 & 2.67 & 3.10 & 5.18 & 8.51 \\
\hline 1993 & 6.03 & 2.70 & 2.57 & 3.28 & 3.21 & 5.88 & 8.96 \\
\hline 1994 & 6.10 & 2.90 & 2.59 & 3.63 & 4.25 & 8.13 & 8.58 \\
\hline 1995 & 6.42 & 3.00 & 2.61 & 3.99 & 6.89 & 9.45 & 7.64 \\
\hline 1996 & 7.25 & 3.10 & 2.66 & 4.37 & 5.25 & 9.66 & 6.63 \\
\hline 1997 & 8.16 & 3.20 & 2.63 & 4.68 & 4.05 & 11.81 & 6.84 \\
\hline 1998 & 9.42 & 3.20 & 2.67 & 5.46 & 3.57 & 13.26 & 6.89 \\
\hline 1999 & 10.21 & 3.30 & 2.74 & 6.30 & 2.49 & 13.04 & 7.69 \\
\hline 2000 & 9.89 & 3.30 & 2.73 & 6.08 & 2.56 & 10.58 & 6.49 \\
\hline 2001 & 9.61 & 3.80 & 2.87 & 6.08 & 2.54 & 8.98 & 8.38 \\
\hline 2002 & 9.37 & 4.20 & 3.05 & 6.60 & 3.00 & 7.88 & 10.36 \\
\hline 2003 & 9.99 & 4.60 & 3.18 & 6.66 & 3.45 & 8.21 & 10.54 \\
\hline 2004 & 9.10 & 4.50 & 3.10 & 7.30 & 3.94 & 7.76 & 10.84 \\
\hline 2005 & 9.57 & 4.50 & 3.10 & 7.95 & 3.56 & 7.12 & 10.64 \\
\hline 2006 & 8.64 & 4.40 & 2.74 & 7.55 & 3.57 & 7.05 & 8.72 \\
\hline 2007 & 8.33 & 4.30 & 2.40 & 8.06 & 3.63 & 6.00 & 8.87 \\
\hline 2008 & 7.34 & 4.60 & 2.27 & 7.21 & 3.87 & 6.20 & 9.71 \\
\hline 2009 & 8.52 & 4.70 & 2.47 & 6.11 & 5.36 & 8.30 & 12.55 \\
\hline 2010 & 7.73 & 4.50 & 2.44 & 5.61 & 5.30 & 7.37 & 10.66 \\
\hline 2011 & 6.92 & 4.50 & 2.52 & 5.15 & 5.17 & 6.54 & 8.80 \\
\hline 2012 & 7.19 & 4.60 & 2.69 & 4.47 & 4.89 & 5.44 & 8.15 \\
\hline 2013 & 6.99 & 4.60 & 2.82 & 4.34 & 4.91 & 5.46 & 8.73 \\
\hline 2014 & 6.67 & 4.60 & 2.77 & 4.05 & 4.81 & 5.16 & 9.88 \\
\hline 2015 & 8.44 & 4.60 & 2.78 & 4.51 & 4.31 & 5.57 & 10.24 \\
\hline 2016 & 11.61 & 4.50 & 2.73 & 4.30 & 3.86 & 5.56 & 10.84 \\
\hline 2017 & 12.83 & 4.40 & 2.56 & 4.18 & 3.42 & 5.21 & 10.82 \\
\hline 2018 & 12.54 & 4.42 & 2.55 & 4.30 & 3.32 & 4.74 & 10.90 \\
\hline
\end{tabular}

Bu çalışmada gelişmekte olan E7 ülkelerinde işsizlik histerisinin geçerliliği incelenecektir. Bu doğrultuda E7 ülkelerine ait 1991-2018 dönemi yıllık işsizlik oranları analize dahil edilmiştir. Öncelikle serilerin doğrusallığ 1 incelenmiştir. Doğrusal özellikte olan işsizlik oranı serilerine yapısal kırılmalı birim kök testleri uygulanmıştır. Doğrusal olmayan serilere ise doğrusal olmayan birim kök testleri uygulanmıştır.

Çalışmanın ilk bölümünde işsizlik histerisine ait genel bilgiler verilmiş, ikinci bölümde ilgili literatür özetlenmiş, üçüncü bölümde veri ve yöntem ele alınmış, dördüncü bölümde bulgular verilmiş ve son bölümde sonuçlar ele alınmıştır. 


\section{İlgili Literatür}

İşsizlik histerisinin geçerliliği ile ilgili yapılan çalışmalar incelendiğinde genellikle birim kök testlerinin uygulandığı görülmektedir. Özellikle güncel çalışmaların çoğunda işsizlik oranlarının doğrusal yapıda olmadığı görülmüş ve doğrusallığın dikkate alındığı güncel test teknikleri kullanılmıştır. Çalışmada gelişmekte olan E7 ülkeleri analize dahil edildiği halde işsizlik histerisi ile ilgili olabildiğince geniş kanıtlar sunan çalışmalar incelenmiştir. Yapılan literatür araştırması özet halinde Tablo 2'de verilmiştir.

Tablo 2. incelendiğinde bulguların farklılık gösterdiği ve henüz işsizlik histerisinin geçerliliği noktasında bir fikir birliğine varılamadığı görülmektedir. Yapılan bazı çalışmalarda işsizlik histerisinin gelişmiş ülkelerde geçerli olduğu ancak gelişmekte olan ülkelerde genellikle geçerli olmadı̆̆ı vurgulanmıştır (Akdoğan, 2017).

Tablo 2. Literatür Özeti

\begin{tabular}{|c|c|c|c|c|c|c|}
\hline & Çalışma & Ülke & Dönem & Frekans & Yöntem & Sonuç \\
\hline \multicolumn{7}{|c|}{ Türkiye } \\
\hline 1 & $\begin{array}{l}\text { (Barışık ve } \\
\text { Çevik, 2008) }\end{array}$ & Türkiye & 1923-2006 & Yillık & $\begin{array}{l}\text { Birim Kök } \\
\text { Testleri ve Yarı } \\
\text { Parametrik Güçlü } \\
\text { Hafıza Modelleri } \\
\end{array}$ & $\begin{array}{l}\text { Türkiye için işsizlik } \\
\text { histerisi geçerlidir. }\end{array}$ \\
\hline 2 & $\begin{array}{ll}\text { (Güloğlu } & \text { ve } \\
\text { Ispir, 2011) } & \end{array}$ & $\begin{array}{l}\text { Türkiye } \\
\text { Sektörel } \\
\text { İşsizlik }\end{array}$ & $1988-2008$ & Yillık & Birim Kök Testleri & $\begin{array}{l}\text { Türkiye'nin } 9 \text { sektörüne ait } \\
\text { işsizlik oranları panel bi- } \\
\text { rim kök testleri ile sınan- } \\
\text { miş ve sonuç olarak işsizlik } \\
\text { histerisi reddedilmiştir. }\end{array}$ \\
\hline 3 & $\begin{array}{l}\text { (Bayrakdar, } \\
\text { 2015) }\end{array}$ & Türkiye & $2000-2013$ & Çeyreklik & Birim Kök Testleri & $\begin{array}{l}\text { İşizilik Histerisi } \\
\text { Geçerlidir }\end{array}$ \\
\hline 4 & $\begin{array}{l}\text { (Güriş, } \\
\text { Tiftikçigil } \\
\text { ve } \\
\text { Tıraşoğlu, 2017) }\end{array}$ & Türkiye & $1970-2014$ & Yillık & Birim Kök Testleri & $\begin{array}{l}\text { Analiz sonucunda Türkiye } \\
\text { işsizlik oranlarının doğru- } \\
\text { sal olmayan yapıda ol- } \\
\text { duğu ve işsizlik histerisi- } \\
\text { nin geçerli olmadığı vur- } \\
\text { gulanmıştır. }\end{array}$ \\
\hline \multicolumn{7}{|c|}{ OECD Ülkeleri } \\
\hline 5 & (Roed, 1996) & $\begin{array}{l}\text { OECD } \\
\text { Ülkeleri }\end{array}$ & 1970-1994 & Çeyreklik & Birim Kök Testleri & $\begin{array}{l}\text { Finlandiya, İtalya, İspanya, } \\
\text { İsveç ve ABD'de işsizlik } \\
\text { histerisi geçerli değilken } \\
\text { analize dahil edilen diğer } \\
\text { ülkelerde geçerlidir. }\end{array}$ \\
\hline 6 & $\begin{array}{l}\text { (C.-C. Lee } \\
\text { ve Chang, 2008) }\end{array}$ & $\begin{array}{l}\text { OECD } \\
\text { Ülkeleri }\end{array}$ & $1855-2004$ & Yillik & Birim Kök Testleri & $\begin{array}{l}\text { Analize dahil edilen } 14 \text { ül- } \\
\text { kenin tamaminda işsizlik } \\
\text { histerisi reddedilmiştir. }\end{array}$ \\
\hline
\end{tabular}




\begin{tabular}{|c|c|c|c|c|c|c|}
\hline 7 & $\begin{array}{l}\text { (Meng, } \\
\text { Strazicich ve } \\
\text { Lee, 2017) }\end{array}$ & $\begin{array}{l}\text { OECD } \\
\text { Ülkeleri }\end{array}$ & $1983-2013$ & Çeyreklik & Birim Kök Testleri & $\begin{array}{l}\text { Analize dahil edilen } 14 \text { ül- } \\
\text { kenin 4'ünde işsizlik histe- } \\
\text { risi, 3'ünde doğal işsizlik } \\
\text { oranı, 7'sinde de yapısalcı } \\
\text { hipotez geçerlidir. }\end{array}$ \\
\hline 8 & $\begin{array}{l}\text { (Khraief, } \\
\text { Shahbaz, } \\
\text { Heshmati } \\
\text { ve Azam, 2018) }\end{array}$ & $\begin{array}{l}\text { OECD } \\
\text { Ülkeleri }\end{array}$ & $1980-2013$ & Yillık & Birim Kök Testleri & $\begin{array}{l}\text { Analize dahil edilen } 29 \text { ül- } \\
\text { keden } 25 \text { 'inde işsizlik histe- } \\
\text { risi reddedilmiştir. Türki- } \\
\text { ye'de doğal işsizlik formu } \\
\text { geçerlidir. }\end{array}$ \\
\hline \multicolumn{7}{|c|}{ Avrupa Ülkeleri } \\
\hline 9 & $\begin{array}{l}\text { (Chang, } \\
\text { Lee, Nieh } \\
\text { ve Wei, 2005) }\end{array}$ & $\begin{array}{l}\text { Avrupa } \\
\text { Ülkeleri }\end{array}$ & 1961-1999 & Yillik & Birim Kök Testleri & $\begin{array}{l}\text { Analize dahil edilen } 10 \text { ül- } \\
\text { keden Belçika ve Hollanda } \\
\text { hariç diğer ülkelerde işsiz- } \\
\text { lik histerisi geçerlidir. }\end{array}$ \\
\hline 10 & $\begin{array}{l}\text { (Klinger ve } \\
\text { Weber, 2016) }\end{array}$ & $\begin{array}{l}\text { ABD ve } \\
\text { Almanya }\end{array}$ & $1960-2015$ & Aylık & $\begin{array}{l}\text { Markov Rejim De- } \\
\text { ğişim Modeli }\end{array}$ & $\begin{array}{l}\text { Almanya için İşsizlik His- } \\
\text { terisi geçerli iken ABD için } \\
\text { geçerli değildir. }\end{array}$ \\
\hline 11 & (Furuoka, 2017a) & $\begin{array}{l}\text { Avrupa } \\
\text { Ülkeleri }\end{array}$ & $1991-2015$ & Yillık & Birim Kök Testleri & $\begin{array}{l}\text { Analize dahil edilen } 5 \text { ül- } \\
\text { kenin } 4 \text { 'ünde işsizlik histe- } \\
\text { risi geçerlidir. }\end{array}$ \\
\hline 12 & (Akdoğan, 2017) & $\begin{array}{l}\text { Avrupa, } \\
\text { ABD, } \\
\text { Japonya }\end{array}$ & 1983-2014 & Çeyreklik & Birim Kök Testleri & $\begin{array}{l}\text { Analize dahil edilen } \\
\text { ülkelerin (Türkiye dahil) } \\
\% 60 \text { 'ında işsizlik histerisi } \\
\text { reddedilmiştir. }\end{array}$ \\
\hline 13 & $\begin{array}{l}\text { (Obradović, } \\
\text { Ristić ve } \\
\text { Lojanica, 2018) }\end{array}$ & $\begin{array}{l}\text { Güney } \\
\text { Doğu } \\
\text { Avrupa } \\
\text { Ülkeleri }\end{array}$ & 2005-2017 & Çeyreklik & Birim Kök Testleri & $\begin{array}{l}\text { Analize dahil edilen } 10 \text { ül- } \\
\text { kenin } 8 \text { 'inde İşsizlik Histe- } \\
\text { risi geçerliyken Türkiye'de } \\
\text { doğal işsizlik formu geçer- } \\
\text { lidir. }\end{array}$ \\
\hline \multicolumn{7}{|c|}{ Gelişmekte Olan ve Diğer Ülkeler } \\
\hline 14 & $\begin{array}{l}\text { (Gustavsson ve } \\
\text { Österholm, 2006) }\end{array}$ & $\begin{array}{l}\text { Avust- } \\
\text { ralya, } \\
\text { Kanada, } \\
\text { Finlan- } \\
\text { diya, } \\
\text { İsveç } \\
\text { ve ABD } \\
\end{array}$ & 1948-2005 & Aylık & Birim Kök Testleri & $\begin{array}{l}\text { Avustralya dişında diğer } \\
\text { ülkelerde işsizlik histerisi } \\
\text { geçerli değildir. }\end{array}$ \\
\hline 15 & $\begin{array}{l}\text { (Munir ve } \\
\text { Ching, 2015) }\end{array}$ & $\begin{array}{l}\text { Geliş- } \\
\text { mekte } \\
\text { Olan } \\
\text { Asya } \\
\text { Ülkeleri } \\
\end{array}$ & $1980-2009$ & Yillık & Birim Kök Testleri & $\begin{array}{l}\text { Panel birim kök testleri so- } \\
\text { nucunda analize dahil edi- } \\
\text { len ülkelerde işsizlik histe- } \\
\text { risi geçerli değildir. }\end{array}$ \\
\hline 16 & (Furuoka, 2017b) & $\begin{array}{l}\text { İskandi- } \\
\text { nav } \\
\text { Ülkeleri }\end{array}$ & $2000-2014$ & Çeyreklik & Birim Kök Testleri & $\begin{array}{l}\text { Analize dahil edilen } 4 \text { ül- } \\
\text { kenin hepsinde işsizlik his- } \\
\text { terisi reddedilmiştir. }\end{array}$ \\
\hline 17 & $\begin{array}{l}\text { (Akkuş ve } \\
\text { Topuz, 2019) }\end{array}$ & $\begin{array}{l}\text { En } \\
\text { Kırılgan } \\
\text { Beşli } \\
\end{array}$ & $1980-2016$ & Yillik & Birim Kök Testleri & $\begin{array}{l}\text { Türkiye dahil analize dahil } \\
\text { edilen } 5 \text { ülkede de işsizlik } \\
\text { histerisi geçerlidir. }\end{array}$ \\
\hline 18 & $\begin{array}{l}\text { (Yaya, } \\
\text { Ogbonna ve } \\
\text { Mudida, 2019) }\end{array}$ & $\begin{array}{l}\text { Afrika } \\
\text { Ülkeleri }\end{array}$ & 1991-2017 & Yillık & Birim Kök Testleri & $\begin{array}{l}\text { Analize dahil edilen } 42 \text { ül- } \\
\text { kenin } 7 \text { 'sinde işsizlik histe- } \\
\text { risi geçerli iken diğer ülke- } \\
\text { lerde geçerli değildir. }\end{array}$ \\
\hline
\end{tabular}




\section{Veri Seti}

Çalışmada E7 ülkelerinin 1991-2018 yıllarına ait işsizlik verileri kullanılmıştır. Mevsimsel değişimlerin etkisinden kurtulmak için veriler yıllık frekansta oluşturulmuş ve veri seti Dünya Bankası veri tabanından elde edilmiştir. Çalışmaya dahil edilen ülkeler, kısaltmaları ve tanımlayıcı istatistikler Tablo 3'te gösterilmiştir. Ayrıca serilere ait zamanyolu grafikler Şekil 1'de verilmiştir. Tablo 3'e göre en yüksek ortalama işsizlik oranı Türkiye'de gerçekleşmiştir. Onu sırasıyla Brezilya ve Rusya izlemiştir. En düşük işsizlik oranı ise Hindistan'da gözlemlenmektedir

Tablo 3. Tanımlayıcı İstatistikler

\begin{tabular}{lllll}
\hline Ülke & Kodu & Ortalama & Maksimum & Minimum \\
\hline Brezilya & BRA & 8.4839 & 12.8270 & 6.0300 \\
Çin & CHN & 3.9220 & 4.7000 & 2.4000 \\
Hindistan & IND & 2.6795 & 3.1820 & 2.2680 \\
Endonezya & IDN & 5.2658 & 8.0600 & 2.5400 \\
Meksika & MEX & 3.9762 & 6.8880 & 2.4880 \\
Rusya & RUS & 7.5224 & 13.2610 & 4.7440 \\
Türkiye & TUR & 9.1447 & 12.5520 & 6.4950 \\
\hline
\end{tabular}

BRA

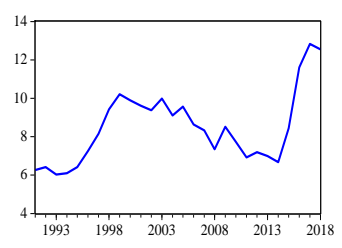

IDN

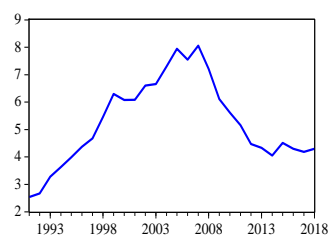

TUR

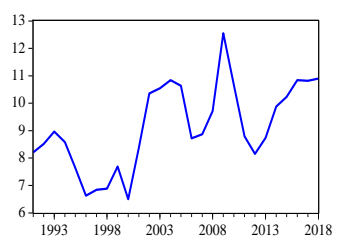

CHN

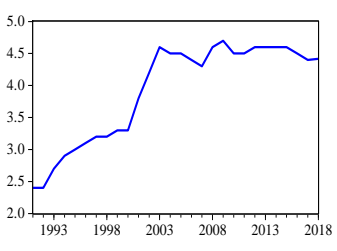

MEX
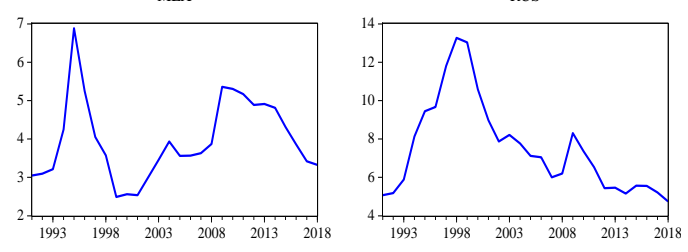

Şekil 1. Serilere Ait Zamanyolu Grafikleri 


\section{Metodoloji}

Çalışmanın amacı E7 ülkelerinde işsizlik histerisinin geçerliliğini test etmektir. Bu amaç doğrultusunda serilerin durağanlığı incelenecektir. Doğrusal olmayan zaman serileri için klasik birim kök testleri sapmalı sonuçlar verebilecektir. Bu nedenle çalışmada öncelikle doğrusallık testi uygulanmış ve serilerin doğrusal olup olmaması durumuna göre uygulanacak birim kök testleri belirlenmiştir. Doğrusallık testi olarak (Harvey, Leybourne ve Xiao, 2008)' in metodolojisi uygulanmıştır. Metodolojinin yazımında Gozbasi vd. (2014), K1liç ve Buğan (2016) ve Buğan vd. (2019) 'nin çalışmalarından yararlanılmıştır.

Harvey vd. (2008), serilerin durağanlığı I(0) olduğunda aşağıdaki modeli geliştirmişlerdir;

$$
y_{t}=\beta_{0}+\beta_{1} y_{t-1}+\beta_{2} y_{t-1}^{2}+\beta_{3} y_{t-1}^{3}+\sum_{j=1}^{p} \beta_{4, j} \Delta y_{t-j}+\varepsilon_{t}
$$

Denklem (1) için temel ve alternatif hipotezler şu şekilde olacaktır;

$$
\begin{aligned}
& H_{0,0}: \beta_{2}=\beta_{3}=0 \\
& H_{1,0}: \beta_{2} \neq 0 / \beta_{3} \neq 0
\end{aligned}
$$

Bu durumda Wald istatistiği şu şekilde hesaplanacaktır;

$$
W_{0}=T\left(R S S_{0}^{r} / R S S_{0}^{u}-1\right)
$$

ve kısıtlanmamış EKK regresyonuna (1) ait artıkların kareleri toplamını temsil etmektedir.

Serilerin I(1) olduğu durumlarda ise;

$$
\Delta y_{t}=\lambda_{1} \Delta y_{t-1}+\lambda_{2}\left(\Delta y_{t-1}\right)^{2}+\lambda_{3}\left(\Delta y_{t-1}\right)^{3}+\sum_{j=2}^{p} \lambda_{4, j} \Delta y_{t-j}+\varepsilon_{t}
$$

Denklem (2) için temel ve alternatif hipotez şu şekilde olacaktır;

$$
\begin{aligned}
& H_{0,1}: \lambda_{2}=\lambda_{3}=0 \\
& H_{1,1}: \lambda_{2} \neq 0 / \lambda_{3} \neq 0
\end{aligned}
$$

Bu durumda Wald istatiği şu şekilde hesaplanacaktır;

$$
W_{1}=T\left(R S S_{1}^{r} / R S S_{1}^{u}-1\right)
$$

$R S S_{0}^{r}$ ve $R S S_{0}^{u}$ kısıtlanmamış EKK regresyonuna (2) ait artıkların kareleri toplamını temsil etmektedir. 
Seriler durağan olduğunda I(0), W0; birim kök içerdiğinde I(1) ise W1 kullanılacaktır. Ancak serilerin durağanlığı bilinmediği durumlarda ağırlıklandırılmış ortalama test istatistiği kullanılmaktadır:

$$
W_{\lambda}=\{1-\lambda\} W_{0}+\lambda W_{1}
$$

Çalışmada endekslere ait $W_{\lambda}$ istatistikleri hesaplanmıştır.

Doğrusal olmayan serilere. (Kapetanios, Shin ve Snell, 2003) ve (Kruse, 2011) tarafından geliştirilen birim kök testleri uygulanacaktır. Kapetanios vd. (2003), serilerde birim kök olduğuna dair kurulan temel hipotezi doğrusal olmayan üstel düzgün geçişli model (ESTAR- Exponential Smooth Transition Autoregressive) ile test etmiştir. Kapetanios vd. (2003), ESTAR sürecini şu şekilde önermiştir:

$$
\Delta y_{t}=a y_{t-1}+\phi y_{t-1}\left(1-\exp \left\{-\gamma\left(y_{t-1}-c\right)^{2}\right\}\right)+\varepsilon_{t}
$$

$\varepsilon_{t} \sim \operatorname{iid}\left(0, \sigma^{2}\right) . \mathrm{a}=0$ kisitı altında;

$$
\Delta y_{t}=\phi y_{t-1}\left(1-\exp \left\{-\gamma\left(y_{t-1}-c\right)^{2}\right\}\right)+\varepsilon_{t}
$$

$\mathrm{c}=0$ kisitı altında;

$$
\Delta y_{t}=\phi y_{t-1}\left(1-\exp \left\{-\gamma y_{t-1}^{2}\right\}\right)+\varepsilon_{t}
$$

Yardımc regresyon;

$$
\Delta y_{t}=\beta_{1} y_{t-1}^{3}+u_{t}
$$

Şeklinde kurulmaktadır. Kapetanios vd. (2003), Dickey-Fuller tipi t-testi ile temel ( $H_{0}: \beta_{1}=0$ ) ve alternatif ( $\left.H_{1}: \beta_{1}<0\right)$ hipotezlerini, KSS ismiyle şu şekilde geliştirmişlerdir;

$$
K S S \Rightarrow \frac{1 / 4 W(1)^{4}-3 / 2 \int_{0}^{1} W(r)^{2} d r}{\left(\int_{0}^{1} W(r)^{6}\right)^{1 / 2}}
$$

Kapetanios vd. (2003), düzgün geçiş fonksiyonundaki c parametresinin s1fıra eşit olduğunu varsaymışlardır. Ancak yapılan ampirik çalışmalarla c parametresinin finansal ve ekonomik zaman serilerinde sıfıra eşit olmasının güç olduğu ortaya konulmuştur (Kruse, 2011).

Kruse (2011), düzgün geçiş fonksiyonundaki c parametresinin sıfıra eşit olmadığı durumlara da izin veren doğrusal olmayan bir model önermiştir: 


$$
\Delta y_{t}=\beta_{1} y_{t-1}^{3}+\beta_{2} y_{t-1}^{2}+\beta_{3} y_{t-1}+u_{t}
$$

Testin gücünü artırmak için $\beta_{3}=0$ varsayımı altında model şu hali almıştır:

$$
\Delta y_{t}=\beta_{1} y_{t-1}^{3}+\beta_{2} y_{t-1}^{2}+u_{t}
$$

$\beta_{1}=\gamma \phi$ ve $\beta_{2}=-2 c \gamma \phi$. Temel ve alternatif hipotezler şu şekilde kurulmuştur;

$$
\begin{aligned}
& H_{0}: \gamma=0 \quad\left(10 \text { numaralı regresyon modelinde; } H_{0}: \beta_{1}=\beta_{2}=0\right) \\
& \left.H_{1}: \gamma>0 \quad \text { (10 numaralı regresyon modelinde; } H_{1}: \beta_{1}<0, \beta_{2} \neq 0\right) .
\end{aligned}
$$

Abadir ve Distaso (2007) tarafından önerilen standart Wald test istatistiği hesaplandıktan sonra doğrusal olmayan ESTAR yeni birim kök testinin test istatistiği şu şekilde hesaplanmaktadır:

$$
\tau=t_{\beta_{2}^{\perp}=0}^{2}+1(\hat{\beta}<0) t_{\beta_{1}=0}^{2}
$$

Bu çalışmada da karşılaştırma yapmak amaciyla hem KSS, hem de test istatistikleri hesaplanmıştır.

\section{Bulgular}

Çalışmada serilere öncelikle Harvey vd. (2008) doğrusallık testi uygulanmış ve sonuçlar Tablo 4'te gösterilmiştir. Tablo 4'e göre Çin, Hindistan, Meksika

\begin{tabular}{|c|c|c|c|}
\hline Ülke & Harvey T.İst. $W_{\lambda}$ & Ülke & Harvey T.íst. $W_{\lambda}$ \\
\hline BRA & 3.7 & MEX & $20.06^{* * *}$ \\
\hline CHN & $7.03^{* *}$ & RUS & 1.08 \\
\hline IND & $7.34^{* *}$ & TUR & $7.52^{* *}$ \\
\hline IDN & 1.72 & & \\
\hline
\end{tabular}
ve Türkiye işsizlik oranı serileri doğrusal değildir. Buna karşılık Brezilya, Endonezya ve Rusya doğrusal yapıdadır. Dolayısıyla doğrusal ve doğrusal olmayan serilere farklı birim kök testleri uygulanacaktır.

Tablo 4. Doğrusallık Testi Sonuçlan ğerler, Harvey vd. (2008)'in makalesinden alınmıştır.

Ülkelere ait işsizlik oranı serileri birim kök içeriyorsa söz konusu ülkeler için işsizlik histerisinin varlığından söz edilebilir. Serilerde birim kökün varlığı, dışsal şoklar neticesinde serilerin tekrar ortalamaya dönme eğilimi göstermediği anlamina gelmektedir. 
Doğrusal özellikte olan Brezilya, Endonezya ve Rusya işsizlik oranı serilerine bir ve iki yapısal kırılmalı birim kök testleri uygulanmıştır. Bir kırılmalı testler için ADF temelli Zivot ve Andrews (1992) ve LM temelli Lee ve Strazicich (2013) metodolojileri uygulanmıştır. İki kırılmalı testler için ise yine ADF temelli Narayan ve Popp (2010) ve LM temelli Lee ve Strazicich (2003) metodolojileri uygulanmıştır. Testlere ait sonuçlar Tablo 5 'te özetlenmiştir.

Tablo 5'e bakıldığında Brezilya işsizlik oranı bir kırılmalı birim kök testi sonuçlarına birim kök içermekte iken iki kırılmalı birim kök testi sonuçlarına göre durağandır. İki yapısal kırılma ile durağanlık sağlandığına göre seri durağan kabul edilebilir. Bu durumda Brezilya için işsizlik histerisi hipotezi reddedilecektir. Benzer durum Rusya ve Endonezya işsizlik oranları için de geçerlidir. Dolayısıyla doğrusal olan her 3 ülke işsizlik oranları düzey değerde durağan bulunmuş ve işsizlik histerisi hipotezi reddedilmiştir.

Tablo 5. Doğrusal Kınlmalı Birim Kök Testi Sonuçlarn

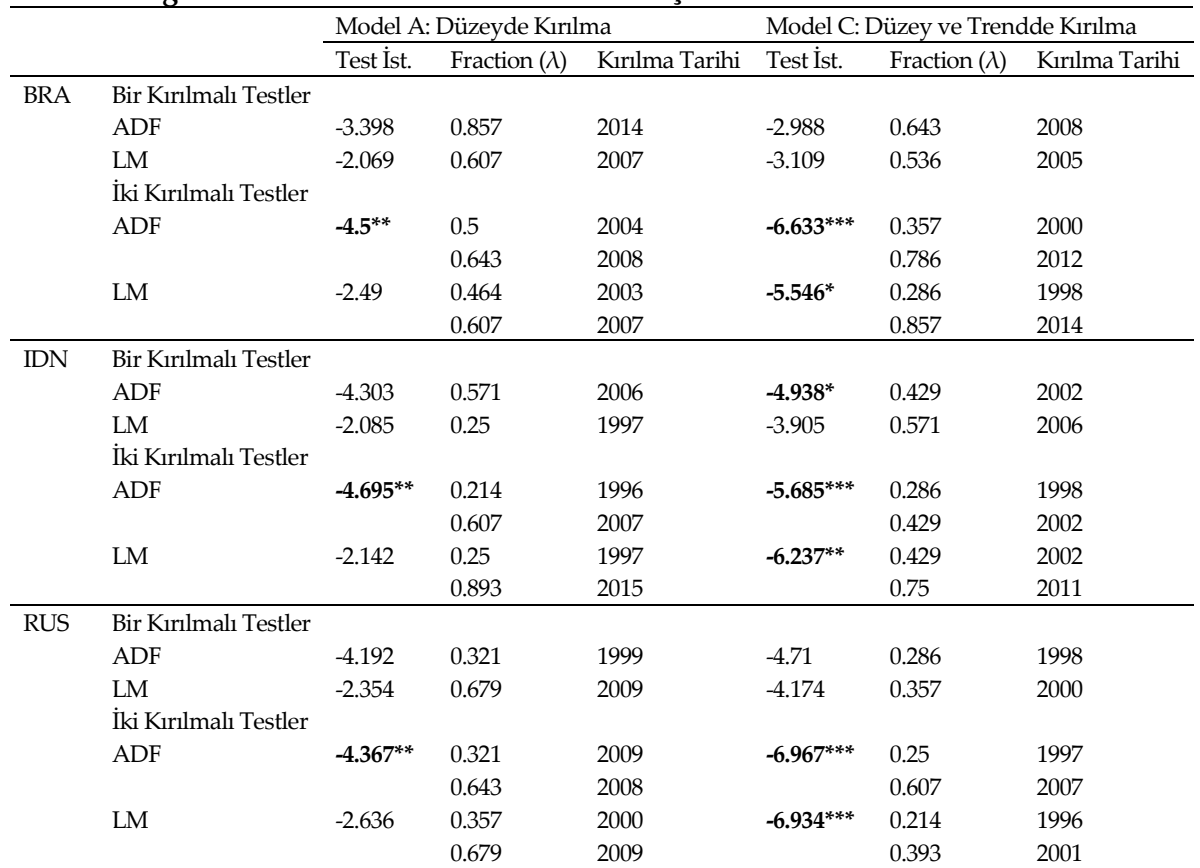

*,** ve *** strasılyla \%10, \%5 ve \%1 düzeyinde istatistiksel olarak anlamllh̆ğı temsil etmektedir. Kritik değerler, Lee ve Strazicich (2003), Lee ve Strazicich (2013), Narayan ve Popp (2010), Zivot ve Andrews (1992) çalışmalarından alınmıştır. 
Doğrusal olmayan Çin, Hindistan, Meksika ve Türkiye işsizlik oranları için Kapetanios vd. (2003) ve Kruse (2011) doğrusal olmayan birim kök testleri uygulanmış ve sonuçlar Tablo 6' da verilmiştir. Tablo 6'ya göre Çin işsizlik oranları birim kök içermekte iken Endonezya, Meksika ve Türkiye işsizlik oranları düzey değerde durağandır. Dolayısıyla Çin için işsizlik histerisi hipotezi kabul edilecek ve Endonezya, Meksika ve Türkiye için reddedilecektir. Tüm E7 ülkeleri için bulgular ele alındığında sadece Çin için işsizlik histerisinin varlığına dair kanıtlar elde edilmiş, diğer ülkeler için işsizlik histerisinin geçerliliğine dair bulgular elde edilmemiştir.

Tablo 6. Doğrusal Olmayan Birim Kök Testleri

\begin{tabular}{|c|c|c|c|c|c|c|c|}
\hline & \multirow[b]{2}{*}{ Lag } & \multicolumn{3}{|l|}{ KSS } & \multicolumn{3}{|l|}{$\tau$} \\
\hline & & Model 1 & Model 2 & Model 3 & Model 1 & Model 2 & Model 3 \\
\hline \multirow[t]{3}{*}{$\mathrm{CHN}$} & 1 & 0.29 & -2.34 & -2.14 & $11.28^{* *}$ & 5.40 & 4.48 \\
\hline & 2 & 0.27 & -1.34 & -1.92 & $8.33^{*}$ & 1.82 & 3.67 \\
\hline & 3 & 0.33 & -1.40 & -1.78 & $8.54^{*}$ & 1.87 & 3.13 \\
\hline \multirow[t]{3}{*}{ IND } & 1 & -0.05 & $-2.93^{* *}$ & -2.90 & 7.18 & $11.99^{* *}$ & $11.64^{*}$ \\
\hline & 2 & -0.06 & $-2.73^{*}$ & -2.74 & 5.40 & $11.97^{* *}$ & $11.98^{*}$ \\
\hline & 3 & -0.42 & $-2.78^{*}$ & -2.78 & 5.86 & $16.63^{* * *}$ & $16.69^{* *}$ \\
\hline \multirow[t]{3}{*}{ MEX } & 1 & -1.89 & $-4.73^{* * *}$ & $-4.52^{* * *}$ & $21.64^{* * *}$ & $21.46^{* * *}$ & $20.01^{* * *}$ \\
\hline & 2 & -1.68 & $-4.53^{* * *}$ & $-4.28^{* * *}$ & $22.61^{* * *}$ & $19.59^{* * *}$ & $17.91^{* * *}$ \\
\hline & 3 & -1.72 & $-4.57^{* * *}$ & $-4.29^{* * *}$ & $20.15^{* * *}$ & $19.99^{* * *}$ & $18.12^{* * *}$ \\
\hline \multirow[t]{3}{*}{ TUR } & 1 & -0.69 & $-3.61^{* * *}$ & $-4.63^{* * *}$ & $9.15^{*}$ & $13.06^{* *}$ & $20.98^{* * *}$ \\
\hline & 2 & -0.35 & $-3.24^{* *}$ & $-4.12^{* * *}$ & 5.99 & $10.38^{* *}$ & $16.58^{* *}$ \\
\hline & 3 & 0.04 & $-2.70^{*}$ & $-3.41^{* *}$ & 4.16 & 7.19 & 11.27* \\
\hline \multirow[t]{3}{*}{ Kritik Değerler } & $\% 1$ & -2.82 & -3.48 & -3.93 & 13.15 & 13.75 & 17.1 \\
\hline & $\% 5$ & -2.22 & -2.93 & -3.4 & 9.53 & 10.17 & 12.82 \\
\hline & $\% 10$ & -1.92 & -2.66 & -3.13 & 7.85 & 8.6 & 11.1 \\
\hline
\end{tabular}

*,** ve *** strastyla \%10, \%5 ve \%1 düzeyinde istatistiksel olarak anlamlih̆̆g temsil etmektedir.

\section{Sonuç}

Dünya ekonomilerinde yükselen ülkeleri gösteren E7 ülkelerinin, dünya gayrisafi yurtiçi hasılasından almış olduğu pay son yıllarda gittikçe artmaktadır. Bununla birlikte dünyayı etkileyen krizlerden bu ülkeler de gelişmiş ülkeler gibi etkilenmektedir. Bunun sonucunda işsizlik gibi sosyal boyutu olan ekonomik problemler de ortaya çımaktadır. Ekonomi yönetimleri bu problemleri istihdam politikaları ile aşmaya çalışırken işsizlik histerisi gibi ekonomi literatüründeki farklı sorunlarla karşılaşabilmektedir. 
Bu çalışmada E7 ülkelerinde işsizlik histerisinin geçerliliğine ilişkin doğrusal yapısal kırılmalı ve doğrusal olmayan birim kök testleri uygulanmıştır. Buna göre E7 ülkelerinde Çin dışında işsizlik histerisinin geçerli olmadığı ortaya konulmuştur. Çin'in işsizlik oranları dışındaki diğer ülke işsizlik oranları şoklardan sonra ortalamaya dönme eğiliminde değildir. Bunun için hükümetlerin işsizlik ile ilgili politikalar geliştirirken daha aktif ve etkin istihdam politikaları belirlemesi gerekmektedir. 


\title{
EXTENDED ABSTRACT
}

\section{Examining Validation of Unemployment Hysteresis: An Empirical Study on E7 Countries}

\author{
Yusuf Bozgeyik \\ Gaziantep University
}

Unemployment, which is defined as those who want to work at the data wage level but cannot find a job, is one of the main problems of developing countries. When it comes to other economic problems such as inflation, it becomes a more rooted problem for emerging economies. The relationship between inflation and unemployment, which was announced with the Philips curve in 1956, began to be questioned with the 1970 oil crisis and led to the emergence of different economic policies with the stagflation crisis.

High unemployment solutions for many years for developing countries such as Turkey are among the outstanding fundamental economic problems. Achieving natural unemployment, which shows the unemployment rate at full employment level, is the main target of economic administrations in employment policies. The unemployment rate, which hovered at single digits between 1980 and 2000, reached double digits with the February 2001 crisis and is now around 13\%.

Considering the long-term unemployment figures in Turkey (in this case, it is generally accepted as the natural rate of unemployment), said that the absence of hysteria unemployment in the economy. Why the rise of unemployment in developing countries such as Turkey said to be based on the economic crisis.

In developing countries in a similar way to Turkey, showing the E7 emerging economies (Emerging Seven- Brazil, China, India, Indonesia, Mexico, Russia, and Turkey), it is generally in the country's unemployment hysteria. The reason for the high rate of unemployment in these countries is to look for other economic factors that affect unemployment, other than hysteria. E7 countries, like the EU countries, were affected by the economic crisis after the 2008 mortgage crisis, and unemployment rates were negatively affected by this situation. 
This study will examine the validity of the unemployment hysteria in developing E7 countries. Accordingly, the annual unemployment rates of the E7 countries for the period 1991-2018 are included in the analysis. First of all, the linearity of the series was examined. Structural fracture unit root tests were applied to the unemployment rate series, which are linear. Nonlinear series were applied to non-linear unit root tests.

In the study, the unemployment data of E7 countries between 19912018 were used. To get rid of the effects of seasonal changes, the data were created on an annual frequency, and the data set was obtained from the World Bank database.

The study aims to test the validity of the unemployment hysteria in E7 countries. For this purpose, the stationarity of the series will be examined. Classical unit root tests for non-linear time series may yield deviated results. For this reason, firstly, the linearity test was applied, and the unit root tests to be applied according to whether the series is linear or not were determined. The methodology of (Harvey, Leybourne, and Xiao, 2008) was applied as the linearity test.

The share of E7 countries, which show the rising countries in the world economies, has been increasing in recent years from the gross domestic product of the world. However, these countries are affected by the crises affecting the world like developed countries. As a result, economic problems with social dimensions such as unemployment also arise. While economic administrations try to overcome these problems with employment policies, they may encounter different problems in economic literature such as unemployment hysteria.

In this study, linear structural break and non-linear unit root tests on the validity of unemployment hysteresis were applied in E7 countries. Accordingly, it has been demonstrated that unemployment hysteria is not valid in E7 countries except China. Unemployment rates in other countries, other than China's unemployment rates, do not tend to return to average after shocks. For this, governments need to set different employment policies when developing unemployment policies. 


\section{Kaynakça / References}

Abadir, K. M. ve Distaso, W. (2007). Testing joint hypotheses when one of the alternatives is one-sided. Journal of Econometrics, 140(2), 695-718. doi:10.1016/j.jeconom.2006.07.022

Akdoğan, K. (2017). Unemployment hysteresis and structural change in Europe. Empirical Economics, 53(4), 1415-1440. doi:10.1007/s00181-016-1171-8

Akkuş, Ö. ve Topuz, S. G. (2019). Validity of unemployment hysteresis: The most fragile five developing countries. Sosyoekonomi, 27(39), 69-80. doi:10.17233/sosyoekonomi.2019.01.04

Barışık, S. ve Çevik, E. İ. (2008). Yapısal kırılma testleri ile Türkiye'de işsizlik histerisinin analizi: 1923-2006 Dönemi. KMU İ̈BF Dergisi, 10(14), 109-134.

Bayrakdar, S. (2015). Türkiye için işsizlik histerisi ya da doğal işsizlik oranı hipotezinin geçerliliğinin sınanması. İktisat Politikası Araştırmaları Dergisi, 2(2), 45-61.

Buğan, M. F., Çevik, E. İ. ve Çevik, N. K. (2019). Katılım 30 Endeksi İçin Zayif Formda Etkin Piyasa Hipotezinin ARFIMA-FIEGARCH Model ile Analizi. Ĭğdır Üniversitesi Sosyal Bilimler Dergisi, 2019(5), 219-241.

Chang, T., Lee, K.-C., Nieh, C.-C. ve Wei, C.-C. (2005). An empirical note on testing hysteresis in unemployment for ten European countries: Panel SURADF approach. Applied Economics Letters, 12(14), 881-886. doi:10.1080/13504850500365871

Furuoka, F. (2017a). A new test for analysing hysteresis in European unemployment. Applied Economics Letters, 24(15), 1102-1106. doi:10.1080/13504851.2016.1257209

Furuoka, F. (2017b). A new approach to testing unemployment hysteresis. Empirical Economics, 53(3), 1253-1280. doi:10.1007/s00181-016-1164-7

Gozbasi, O., Kucukkaplan, I. ve Nazlioglu, S. (2014). Re-examining the Turkish stock market efficiency: Evidence from nonlinear unit root tests. Economic Modelling, 38, 381-384. doi:10.1016/j.econmod.2014.01.021

Gustavsson, M. ve Österholm, P. (2006). Hysteresis and non-linearities in unemployment rates. Applied Economics Letters, 13(9), 545-548. doi:10.1080/13504850500401437

Güloğlu, B. ve Ispir, M. S. (2011). Doğal İşsizlik oranı mı işsizlik histerisi mi Türkiye için sektörel panel birim kök sinaması analizi. Ege Akademik Bakis (Ege Academic Review), 11(2), 205-205. doi:10.21121/eab.2011219565 
Güriş, B., Tiftikçigil, B. Y. ve Tıraşoğlu, M. (2017). Testing for unemployment hysteresis in Turkey: Evidence from nonlinear unit root tests. Quality $\mathcal{E}$ Quantity, 51(1), 35-46. doi:10.1007/s11135-015-0292-z

Harvey, D. I., Leybourne, S. J. ve Xiao, B. (2008). A powerful test for linearity when the order of integration is Unknown. Studies in Nonlinear Dynamics $\mathcal{E}$ Econometrics, 12(3). doi:10.2202/1558-3708.1582

Kapetanios, G., Shin, Y. ve Snell, A. (2003). Testing for a unit root in the nonlinear STAR framework. Journal of Econometrics, 112(2), 359-379. doi:10.1016/S0304-4076(02)00202-6

Khraief, N., Shahbaz, M., Heshmati, A. ve Azam, M. (2018). Are unemployment rates in OECD countries stationary? Evidence from univariate and panel unit root tests. The North American Journal of Economics and Finance. doi:10.1016/j.najef.2018.08.021

Kılıç, Y. ve Buğan, M. F. (2016). The efficient market hypothesis: Evidence from Turkey. International Journal of Academic Research in Business and Social Sciences, 6(10), 262-272.

Klinger, S. ve Weber, E. (2016). Detecting unemployment hysteresis: A simultaneous unobserved components model with Markov switching. Economics Letters, 144, 115-118. doi:10.1016/j.econlet.2016.04.027

Kruse, R. (2011). A new unit root test against ESTAR based on a class of modified statistics. Statistical Papers, 52(1), 71-85. doi:10.1007/s00362-009-0204-1

Lee, C.-C. ve Chang, C.-P. (2008). Unemployment hysteresis in OECD countries: Centurial time series evidence with structural breaks. Economic Modelling, 25(2), 312-325. doi:10.1016/j.econmod.2007.06.002

Lee, J. ve Strazicich, M. C. (2003). Minimum lagrange multiplier unit root test with two structural breaks. The Review of Economics and Statistics, 85(4), 10821089. doi:10.1162/003465303772815961

Lee, J. ve Strazicich, M. C. (2013). Minimum LM unit root test with one structural break. Economics Bulletin, 33(4), 2483-2492.

Meng, M., Strazicich, M. C. ve Lee, J. (2017). Hysteresis in unemployment? Evidence from linear and nonlinear unit root tests and tests with non-normal errors. Empirical Economics, 53(4), 1399-1414. doi:10.1007/s00181-016$1196-\mathrm{z}$

Munir, Q. ve Ching, K. S. (2015). Revisiting the Hysteresis Hypothesis in Unemployment in Selected Emerging Economies. International Journal of Economic Perspectives, 9(3), 22-32. 
Narayan, P. K. ve Popp, S. (2010). A new unit root test with two structural breaks in level and slope at unknown time. Journal of Applied Statistics, 37(9), 1425-1438.

Obradović, S., Ristić, L. ve Lojanica, N. (2018). Are unemployment rates stationary for SEE10 countries? Evidence from linear and nonlinear dynamics. Zb. Rad. Ekon. Fak. Rij., 36(2), 559-583.

Roed, K. (1996). Unemployment hysteresis-Macro evidence from 16 OECD countries. Empirical Economics, 21(4), 589-600. doi:10.1007/BF01180703

Yaya, O. S., Ogbonna, A. E. ve Mudida, R. (2019). Hysteresis of unemployment rates in Africa: New findings from Fourier ADF test. Quality \& Quantity, 1-15. doi:10.1007/s11135-019-00894-6

Zivot, E. ve Andrews, D. W. K. (1992). Further Evidence on the Great Crash, the Oil-Price Shock, and the Unit-Root Hypothesis. Journal of Business \& Economic Statistics, 10(3), 251-270. doi:10.1080/07350015.1992.10509904

\section{Kaynakça Bilgisi / Citation Information}

Bozgeyik, Y. (2020). İşsizlik histerisinin geçerliliğin sınanması: E7 ülkelerine ilişkin ampirik bir çalışma. OPUS-Uluslararası Toplum Araştırmalar Dergisi, 15(26), 4316-4333. DOI: 10.26466/opus.730129 